\title{
Structural and functional analysis of ypt2, an essential ras-related gene in the fission yeast Schizosaccharomyces pombe encoding a Sec4 protein homologue
}

\author{
Heinz Haubruck' ${ }^{1}$ Ulrike Engelke, Peter Mertins \\ and Dieter Gallwitz
}

Max-Planck-Institute for Biophysical Chemistry, Department of Molecular Genetics, PO Box 2841, D-3400 Göttingen, FRG

'Present address: Department of Molecular Biology, Cetus Corporation, Emeryville, CA 94608, USA

Communicated by D.Gallwitz

Using the cloned Saccharomyces cerevisiae YPT1 gene as hybridization probe, a gene, designated ypt2, was isolated from the fission yeast Schizosaccharomyces pombe and found to encode a 200 amino acid long protein most closely related to the ypt branch of the ras superfamily. Disruption of the ypt 2 gene is lethal. The bacterially produced ypt2 gene product is shown to bind GTP. A region of the ypt 2 protein corresponding to but different from the 'effector region' of ras proteins is also different from that of ypt1 proteins of different species but identical to the 'effector loop' of the S.cerevisiae SEC4 gene product, a protein known to be required for vesicular protein transport. The $S$.pombe ypt 2 gene under control of the S.cerevisiae GAL10 promoter is able to suppress the temperature-sensitive phenotype of a $S$. cerevisiae sec 4 mutant, indicating a functional similarity of these GTP-binding proteins from the two very distantly related yeasts.

Key words: GTP-binding protein/ras superfamily/Schizosaccharomyces pombe/Sec4p homologue/ypt2 gene

\section{Introduction}

Ras and ras-related proteins constitute a superfamily of eukaryotic proteins which, by a cycle of GDP and GTP binding, are thought to act as regulators in diverse cellular processes (for reviews see Barbacid, 1987; Chardin, 1988; Gallwitz et al., 1989). All of these proteins are on average 200 amino acid residues long, and segments of these proteins, known from X-ray crystallographic analysis of the $\mathrm{H}$-ras protein to interact with the bound guanine nucleotide (Pai et al., 1989), are highly conserved. According to other structural features, at least three families among the superfamily of ras proteins can be distinguished: ras, rho and ypt proteins (Haubruck et al., 1987; Gallwitz et al., 1989).

Except for the Ras proteins in baker's yeast Saccharomyces cerevisiae, whose primary function is to regulate adenylyl cyclase activity (Toda et al., 1985), the cellular function of neither of the multiple ras or ras-like proteins has so far been precisely defined. However, recent genetic, biochemical and cell physiological analyses with baker's yeast lend strong support to the assumption that members of the ypt family regulate the vectorial transport of vesicular structures in the pathways of protein transport (Goud et al., 1988; Schmitt et al., 1988; Segev et al., 1988; Walworth et al., 1989; Baker et al., 1990).
In mammalian cells, the number of ypt proteins (also designated rab) seems to be rather large (Zahraoui et al., 1989). In contrast, only two members of this protein family, the Yptl protein (Gallwitz et al., 1983) and the Sec4 protein (Salminen and Novick, 1987) have been identified in the yeast S.cerevisiae. Both proteins are essential for cell viability (Schmitt et al., 1986; Salminen and Novick, 1987). Whereas conditional-lethal ypt 1 mutants at the nonpermissive temperature accumulate endoplasmic reticulum and are defective in protein secretion and calcium regulation (Schmitt et al., 1988; Segev et al., 1988), the phenotype of sec 4 mutants is characterized by a massive accumulation of small vesicles unable to fuse with the plasma membrane (Goud et al., 1988; Walworth et al., 1989). Whereas the Ypt 1 protein is attached primarily to Golgi membranes (Segev et al., 1988) via a lipid moiety covalently bound to a C-terminal cysteine (Molenaar et al., 1988), the Sec4 protein localizes to post-Golgi vesicles and the plasma membrane (Walworth et al., 1989). Recent cell-free protein transport studies indicate that Yptlp is an essential component for the vesicular transport of proteins from the endoplasmic reticulum to the Golgi complex (Baker et al., 1990).

As the mouse ypt1 protein (Haubruck et al., 1987), also designated rabl (Touchot et al., 1987), is able functionally to replace the YPTl gene product in S.cerevisiae (Haubruck et al., 1989) and is highly enriched in Golgi structures (Segev et al., 1988; M.Puzicha, G.Dressler, H.Haubruck and D. Gallwitz, unpublished), it seems likely that this protein fulfils a similar function also in mammalian cells. However, among the different ypt ( $\mathrm{rab}$ ) proteins identified in mammalian species, no Sec4 homologue has so far been identified.

The fission yeast Schizosaccharomyces pombe, only distantly related to S.cerevisiae but also amenable to easy genetic analyses, is thought to be a better model organism in comparative studies with higher eukaryotes (Russel and Nurse, 1986). As the ras proteins in the two yeasts are integrated into different regulatory pathways (Toda et al., 1985; Fukui et al., 1986), it is expected that a complementary study on the function of other GTP-binding regulatory proteins will be extremely instructive. We here report the isolation of a gene, ypt2, from S.pombe whose product is shown to be a GTP-binding protein functionally identical to the S.cerevisiae Sec4 protein. The ypt 2 gene, like the ypt 1 and the ypt 3 gene described in the accompanying paper (Miyake and Yamamoto, 1990), encodes an essential function, a finding which indicates that the different members of the ypt gene family have vital and very discrete regulatory functions.

\section{Results}

Cloning, sequence and transcripts of the ypt2 gene By Southern blot analysis with HindIII-digested total $S$. pombe DNA and a ${ }^{32} \mathrm{P}$-labelled $0.53 \mathrm{~kb}$ EcoRI-HincII 
fragment of the S.cerevisiae YPT1 protein-coding region as hybridization probe, three hybridizing DNA fragments of $\sim 9,3$ and $0.5 \mathrm{~kb}$ could be identified under moderately strong hybridization conditions $\left(6 \times \mathrm{SSC}, 60^{\circ} \mathrm{C}\right)$. A $9.2 \mathrm{~kb}$ HindIII fragment obtained by shotgun cloning was subjected to restriction endonuclease mapping, and a $2.65 \mathrm{~kb} \mathrm{NcoI}$ fragment found to react with the S.cerevisiae YPT1 hybridization probe (see Figure 5) was cloned into the HincII restriction site of plasmid pUC8 and partially sequenced.

An open reading frame of 200 codons was detected (Figure 1) the amino acid sequence deduced showed clear resemblance to the Ypt1 protein sequence of baker's yeast. The gene, first designated yptl, was renamed ypt 2 after the recent identification in S.pombe of the S.cerevisiae YPT1 gene homologue (Fawell et al., 1989; Miyake and Yamamoto, 1990).

To identify transcripts of the putative gene, RNA blot analysis was performed using as hybridization probes either a $0.5 \mathrm{~kb}$ AccI/SmaI fragment of the protein-coding region (Figure 5) or a $0.95 \mathrm{~kb}$ HincII fragment representing the last 12 codons and $920 \mathrm{bp}$ of $3^{\prime}$ non-translated sequence. With either hybridization probe, three transcripts of $\sim 1350$, 1550 and $1800 \mathrm{nt}$ were observed (Figure 2).

\section{The ypt2 gene product is a GTP-binding protein}

According to DNA sequence analysis, the S.pombe ypt2 gene encodes a protein of 200 amino acid residues with a molecular mass of 22757 daltons. Certain structural features regarded to be diagnostic for ypt proteins, a serine instead of glycine found in position 12 of mammalian ras proteins and two consecutive cysteine residues at the carboxylterminal end, for instance (Haubruck et al., 1987; Gallwitz et al., 1989), are also found in the ypt2 protein. Within the first 170 amino acid residues, the most highly conserved region of ras and ras-related proteins (Gallwitz et al., 1983, 1989; Barbacid, 1987), the ypt2 protein exhibits identities to a degree of 59.3 and $64.7 \%$ with the S.cerevisiae Ypt1 and Sec4 protein respectively, and $76.6 \%$ with the Dictyostelium discoideum sasl gene product (Figure 3). By comparison, the degree of homology in this region with ras proteins from different eukaryotic species ranges between 36 and $39 \%$.

In particular, the S.pombe ypt 2 protein contains the three sequence elements $\mathrm{GX}_{4} \mathrm{GK}^{\mathrm{S}} / \mathrm{T}$ (amino acids $\left.16-22\right), \mathrm{DX}_{2} \mathrm{G}$ (amino acids 64-67) and NKXD (amino acids 122-125) noted to be highly conserved in different families of GTP-binding proteins (Dever $e$ t al., 1987). These sequences, in addition to a fourth region conserved in ras and ras-like proteins, EXSA (amino acids $150-153$ in ypt2p), have recently been shown by X-ray crystallographic analysis of the GTP-bound form of the c-H-ras protein to participate in nucleotide binding (De Vos et al., 1988; Pai et al., 1989).

To verify that the S.pombe ypt 2 protein binds guanine nucleotides, the protein-coding region was inserted into the previously described pUC8-derived vector pLN (Wagner $e t$ al., 1987) and expressed in Escherichia coli. The bacterially produced protein was then subjected to a GTP-blot analysis and found to bind $\left[\alpha{ }^{32} \mathrm{P}\right] \mathrm{GTP}$, although with an apparently lower capacity than the S.cerevisiae Ypt1 protein (Figure 4).

\section{The ypt2 protein is essential for cell viability}

The existence in S.pombe of several genes belonging to the ras superfamily poses the question as to their functional

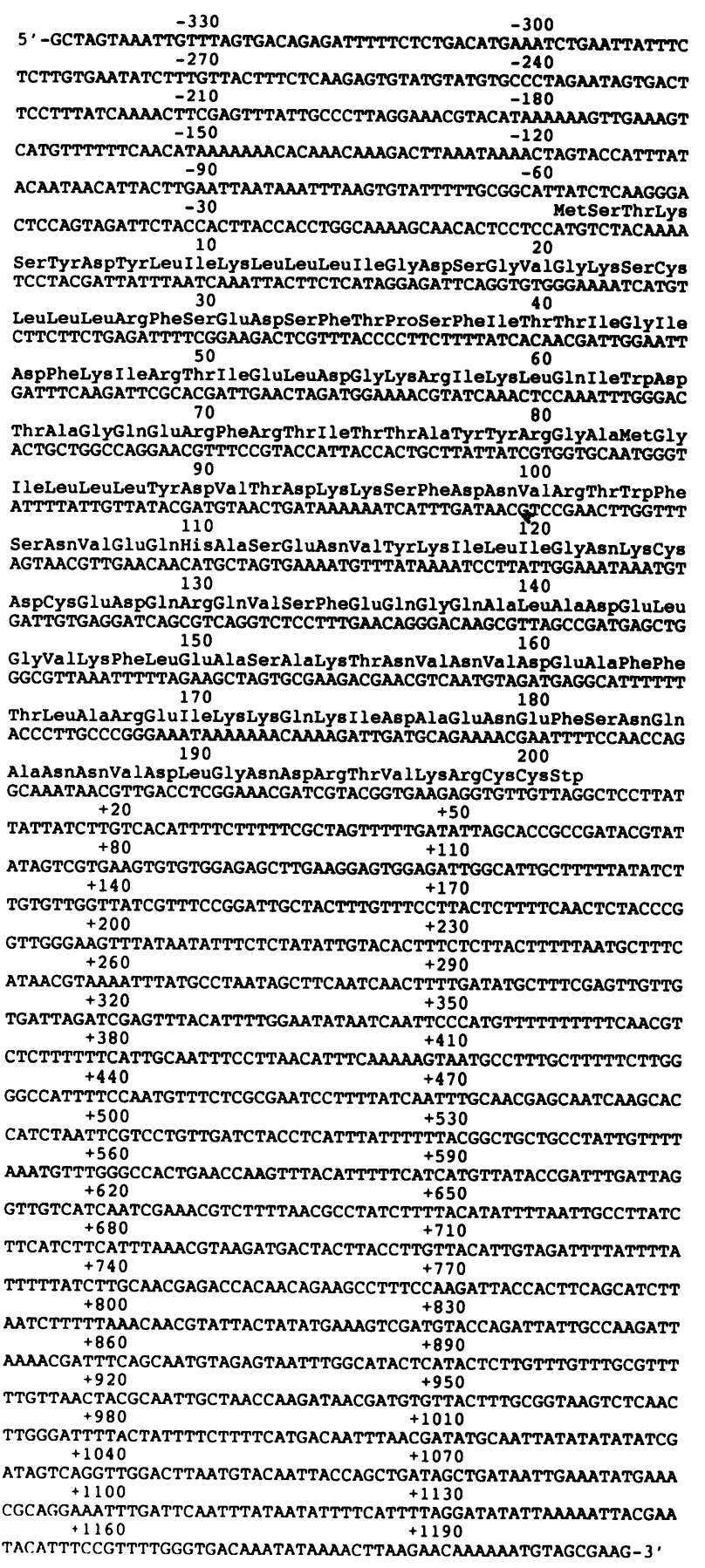

Fig. 1. Nucleotide and deduced amino acid sequence of the $y p t 2$ gene. Nucleotides upstream of the initiation codon are numbered negatively, those downstream of the stop codon (stp) are numbered positively.

interchangeability. As it is fairly easy to inactivate precisely a given chromosomal gene in yeast and to enquire into the dependence for cell viability of its protein product, the ypt 2 gene on one chromosome was disrupted in the $u \mathrm{rat}^{-}$ diploid strain UL130. This was achieved by transforming cells with a linear $4.75 \mathrm{~kb}$ HindIII-Pst I fragment which has the $1.6 \mathrm{~kb} \mathrm{Accl} / \mathrm{ClaI}$ fragment (ypt2 codons 3-200 and $\sim 1000 \mathrm{nt}$ of $3^{\prime}$-untranslated region) replaced by the $S$. pombe ura 4 gene on a $1.8 \mathrm{~kb}$ ClaI fragment (Figure 5). The Southern blot analysis of three $u \mathrm{ra4}^{+}$transformants, showing correct chromosomal integration of the ypt2-disrupting fragment, is presented in Figure 5. After 


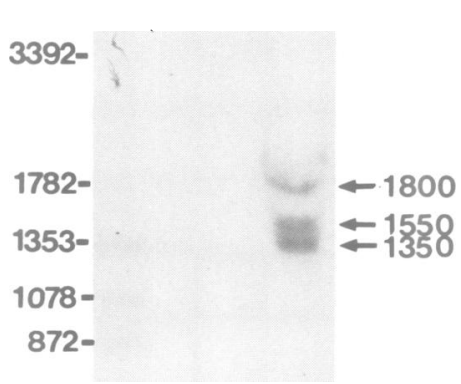

Fig. 2. RNA blot analysis to identify ypt2 gene transcripts. Total cellular RNA was glyoxylated, separated on a $1 \%$ agarose gel and transferred to nitrocellulose. Hybridization was performed with a ${ }^{32} \mathrm{P}$-nick-translated $498 \mathrm{bp} \mathrm{Accl} / \mathrm{SmaI}$ fragment of the protein coding region. The same transcripts were identified with a $953 \mathrm{bp} \mathrm{HincII}$ fragment of the ypt2 3 '-untranslated region. Length markers were HaeIII digest $\phi \times 174$ DNA and S.cerevisiae ribosomal RNAs.

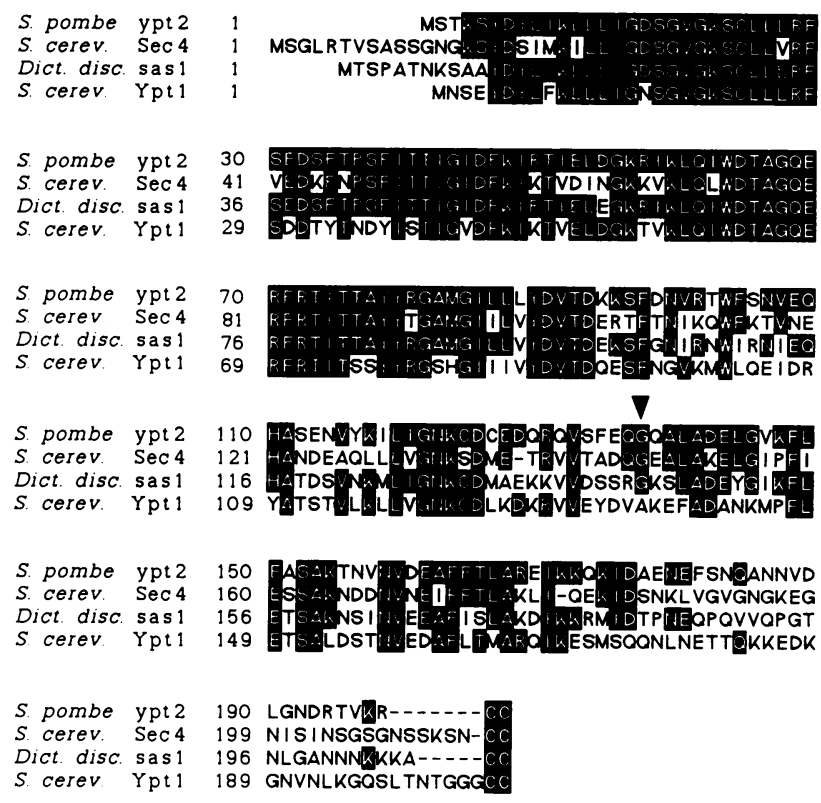

Fig. 3. Comparison of S.pombe ypt2 protein sequence with sequences of other ypt proteins from different species: S.cerevisiae $\operatorname{Sec} 4 \mathrm{p}$ (Salminen and Novick, 1987); Dictyostelium discoideum saslp (Saxe and Kimmel, 1988); S.cerevisiae Yptlp (Gallwitz et al., 1983). Residues identical in the ypt2 protein with those in the other proteins are displayed on dark background. An arrow points to the glycine residue which, when substituted with aspartic acid in the S.cerevisiae Sec4 protein, leads to a temperature-sensitive phenotype (mutation sec4-8). Note the conservation of serine in position 18 (with respect to S.pombe ypt2 protein) and of two cysteine residues at the carboxyl termini, regarded to be typical for ypt proteins (Gallwitz et al., 1989; Haubruck et al., 1989).

sporulation, tetrads analysed from two desired transformants gave rise to not more than two viable spores, all of which were $\mathrm{ura4}^{-}$(Table I). This shows that the ypt2 gene product fulfils an essential function.

\section{S.pombe ypt2 is the functional homologue of S.cerevisiae SEC4}

An amino acid sequence comparison of S.pombe ypt 2 with different ras-related GTP-binding proteins shows that the extent of identities is highest with the Dictyostelium sas 1 and the S.cerevisiae Sec4 protein (Figure 3). Particularly noteworthy is the identical sequence of the three proteins

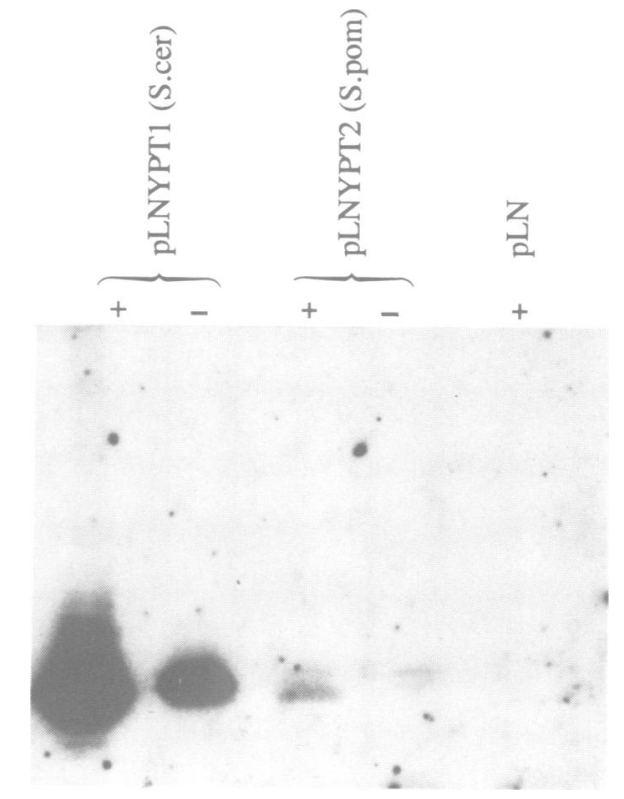

Fig. 4. GTP-blot analysis to show GTP binding of S.pombe ypt2 protein. E.coli cells transformed with either expression vector $\mathrm{pLN}$ or with the same vector carrying the protein-coding region of S.cerevisiae YPT1 (pLNYPT1) or S.pombe ypt2 (pLNYPT2) were uninduced (-) or induced with IPTG $(+)$. Proteins of whole-cell extracts in SDS-containing buffer were separated by SDS-PAGE, transferred to a nitrocellulose filter and treated with $\left[\alpha^{3}{ }^{32} \mathrm{P}\right] \mathrm{GTP}$. According to protein staining, comparable amounts of foreign proteins were present in extracts from pLNYPT1- and pLNYPT2-transformed cells analysed on the gel. Note the slightly faster electrophoretic mobility and the significantly lower capacity for GTP binding of S.pombe ypt2p compared to S.cerevisiae Yptlp.

within a region corresponding to amino acids $32-40$ in mammalian ras proteins, the so-called 'effector region' (Sigal et al., 1986). This region is believed to interact wth GAP, a GTPase-activating protein (Trahey et al., 1988; Vogel et al., 1988). The sequence comparison is presented in Figure 7.

Because of the highly similar primary structures of the S.pombe ypt 2 and the S.cerevisiae Sec4 protein, the latter of which is involved in a late step of protein secretion-the fusion of small vesicles with the plasma membrane (Goud et al., 1988)-we sought to examine whether the ypt 2 protein could rescue a conditional-lethal sec 4 mutant at the nonpermissive temperature. For this purpose, a centromerecontaining vector, YCp50-GPY2 (Figure 6), was constructed carrying the $S$.pombe ypt 2 protein-coding region under transcriptional control of the inducible GAL10 promoter. A temperature-sensitive S.cerevisiae sec $4^{-}$strain, NY405, unable to grow at temperatures higher than $33^{\circ} \mathrm{C}$, was transformed with either the vector YCp50 or the recombinant plasmid YCp50-GPY2. As can be seen in Figure 6, on glucose-containing media untransformed sec 4 cells as well as sec 4 cells harbouring YCp50 or YCp50-GPY2 grew at $25^{\circ} \mathrm{C}$ but not at $37^{\circ} \mathrm{C}$. However, when galactose was used as the sole carbon source to induce the GAL10 promoter, only the cells expressing the S.pombe ypt 2 protein grew well at $37^{\circ} \mathrm{C}$, the non-permissive temperature. This indicates that the S.pombe ypt 2 protein is the functional homologue of the S.cerevisiae Sec4 protein.

In a separate experiment, the S.pombe ypt 2 gene under transcriptional control of the S.cerevisiae GAL10 promoter 


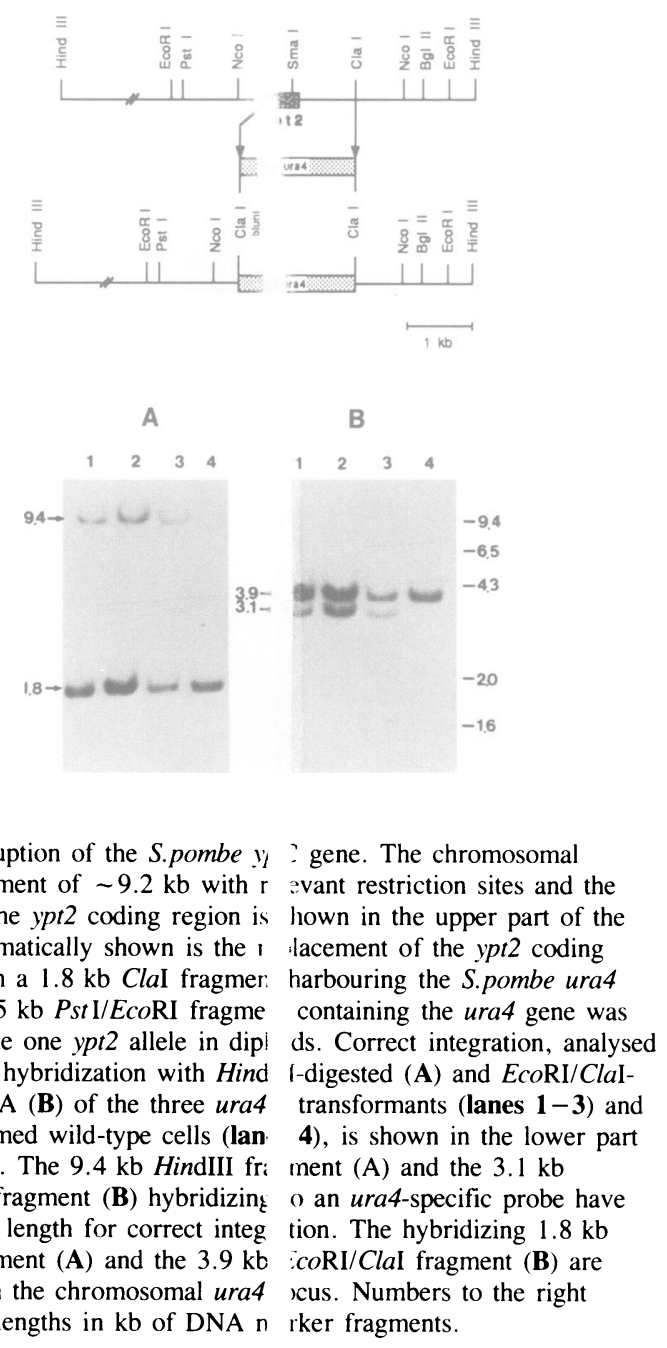

Fig. 5. Disruption of the S.pombe $y$ : gene. The chromosomal HindIII fragment of $-9.2 \mathrm{~kb}$ with $\mathrm{r}$ evant restriction sites and the location of the ypt 2 coding region is hown in the upper part of the figure. Schematically shown is the I lacement of the ypt 2 coding segment with a $1.8 \mathrm{~kb} \mathrm{ClaI}$ fragmer harbouring the S.pombe ura 4 gene. A $4.75 \mathrm{~kb}$ Pst I/EcoRI fragme containing the ura 4 gene was used to delete one ypt 2 allele in dipl ds. Correct integration, analysed by Southern hybridization with Hind 1-digested (A) and EcoRI/ClaIdigested DNA (B) of the three ura4 transformants (lanes 1-3) and non-transformed wild-type cells (lan 4), is shown in the lower part of the figure. The $9.4 \mathrm{~kb} H$ indIII fr: ment (A) and the $3.1 \mathrm{~kb}$ EcoRI/ClaI fragment (B) hybridizing o an ura4-specific probe have the expected length for correct integ tion. The hybridizing $1.8 \mathrm{~kb}$ HindIII fragment (A) and the $3.9 \mathrm{~kb} \quad c 0 \mathrm{RI} / \mathrm{ClaI}$ fragment (B) are derived from the chromosomal ura4 cus. Numbers to the right indicate the lengths in kb of DNA $n$ rker fragments

Table I. Tetrad analysis of two dipl 1 S.pombe transformants after ypt 2 gene disruption

\begin{tabular}{llll}
\hline Transformant $^{a}$ & \multicolumn{3}{l}{$\begin{array}{l}\text { Viable:non-viable : } \\
\text { per tetrad }\end{array}$} \\
\cline { 2 - 4 } & $4: 0$ & $3: 1$ & $2: 2$ \\
\hline UL 148-1 & 0 & 0 & 13 \\
UL 148-2 & 0 & 0 & 13 \\
\hline
\end{tabular}

a Transformants contain the ura 4 ma or gene instead of the protein-coding region of one $y p t 2$ al $\mathrm{e}$.

was used to replace the essentia $Y P T I$ gene in budding yeast. High expression of the ypt2 medium could not rescue the (data not shown), suggesting sec 4 mutant by the ypt 2 gene overproducing another GTP-l

\begin{tabular}{lll}
\hline ires & $\begin{array}{l}\text { Ratio of } \\
\text { ura4 }^{+} / \text {ura }^{-} \text {spores }\end{array}$ \\
\cline { 1 - 2 } 3 & $0: 4$ & \\
\hline & 0 & $0 / 30$ \\
& 0 & $0 / 28$ \\
\hline
\end{tabular}

zne in galactose-containing cerevisiae ypt 1 null mutant lat complementation of the as not simply the result of nding protein.

\section{Discussion}

Small GTP-binding proteins cc stituting the ras superfamily are widely distributed in euka otic organisms. A primary structure comparison of dif rent members of the ras superfamily within one or $b$ ween different eukaryotic species allows the distinction o ieveral subfamilies, ras and ypt (rab) proteins being two' them.

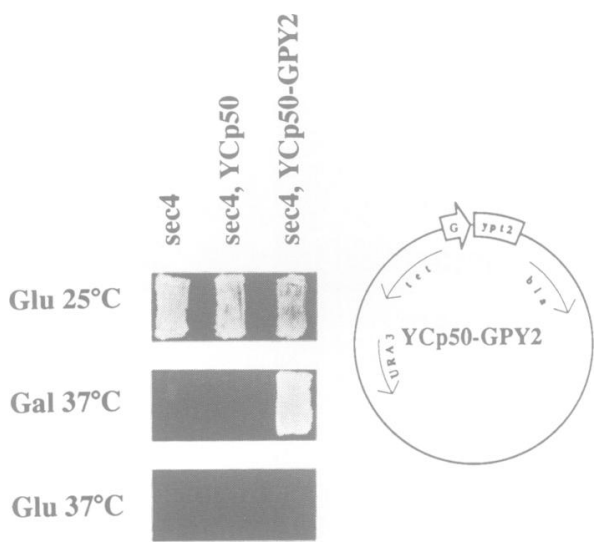

Fig. 6. Complementation by the S.pombe ypt2 gene of a conditionallethal S.cerevisiae sec 4 mutant. The sec 4 mutant strain GUS-1D (sec 4 ura3), unable to grow at temperatures higher than $33^{\circ} \mathrm{C}$, was transformed with either the centromere-containing plasmid YCp50 or the same vector harbouring the S.pombe ypt 2 gene under transcriptional control of the S.cerevisiae GALIO promoter (YCp50-GPY2). Note that at $37^{\circ} \mathrm{C}$ only the transformant expressing S.pombe ypt 2 gene on galactose-containing medium was able to grow.

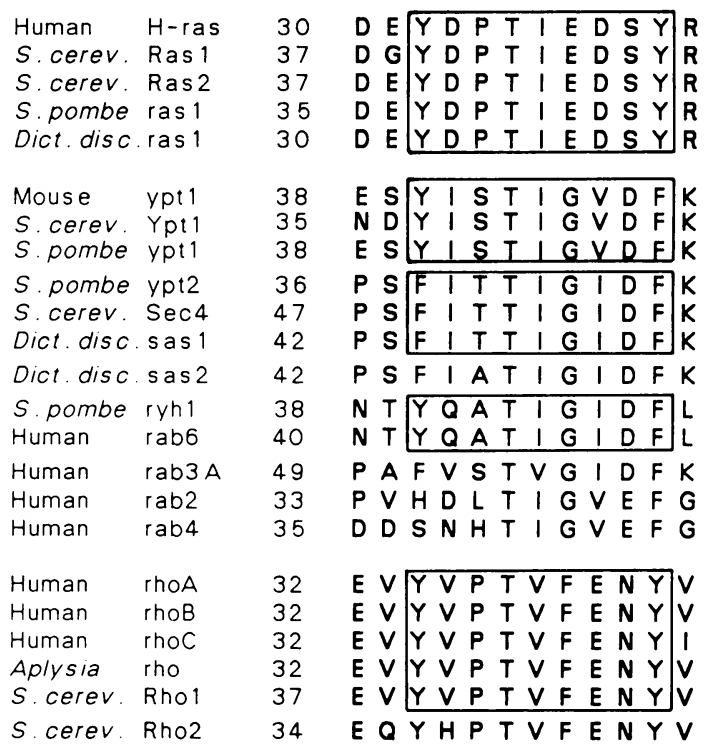

Fig. 7. Comparison of ras and ras-related proteins from different species with respect to sequence segments corresponding to the ras 'effector region' (residues 32-40 in mammalian $\mathrm{H}$-ras proteins). Completely identical sequences are boxed and define highly conserved members of the ras protein superfamily. Source of protein sequence data: ras (Barbacid, 1987); mouse ypt 1 (Haubruck et al., 1987); S.cerevisiae Yptl (Gallwitz et al., 1983); S.pombe yptl (Miyake and Yamamoto, 1990); S.pombe ypt2 (this paper); S.cerevisiae Sec4 (Salminen and Novick, 1987): Dictyostelium discoideum sas1 and sas2 (Saxe and Kimmel, 1988); S.pombe ryhl (Hengst et al., 1990); human rab (Zahraoui et al., 1989); human rho (Chardin et al., 1988;

Yeramian et al., 1987); Aplysia rho and S.cerevisiae Rho (Madaule et al., 1987).

Despite the great effort in several laboratories, the cellular function of the different mammalian ras proteins has not yet been elucidated. In contrast, especially through the help of genetic analyses, the major role of the RASI and RAS2 gene products as regulators of adenylyl cyclase activity in the budding yeast S.cerevisiae was disclosed soon after their discovery (DeFeo-Jones et al., 1983; Powers et al., 1984; Toda et al., 1985). Although mammalian $\mathrm{H}$-ras protein 
expressed in S.cerevisiae suppresses lethality caused by the simultaneous disruption of RASI and RAS2 genes (DeFeoJones et al., 1985; Kataoka et al., 1985), ras proteins in mammalian cells do not regulate adenylyl cyclase (Beckner et al., 1985; Birchmeier et al., 1985). Similarly, the protein product of the single ras 1 gene of the fission yeast S.pombe is not involved in cAMP metabolism (Fukui et al., 1986). This seemingly complicated picture led us to initiate a study of the structure and function of ypt proteins in S.pombe with the final goal to investigate the generality of the model stemming from work with the very distantly related yeast $S$. cerevisiae that members of this protein family are regulators of vesicular transport processes (Bourne, 1988; Goud et al., 1988; Schmitt et al., 1988; Segev et al., 1988).

With regard to highly conserved sequence segments typical for either ras, rho, ypt or other GTP-binding proteins (Gallwitz et al., 1989), three members of the family of ypt proteins have now been identified using different approaches for their isolation. The yptl and ypt3 genes (Miyake and Yamamoto, 1990) as well as the ypt 2 gene described in this report encode different and essential functions.

As the ypt 2 protein contains all the sequence motifs known to be required for guanine-nucleotide binding and GTPase activity, it was not surprising to observe GTP binding of the bacterially produced protein on GTP blots. The seemingly lower apparent capacity for GTP binding of the ypt2 protein compared to that of the S.cerevisiae Ypt1 protein might not be very informative as, for instance, different efficiencies of protein renaturation on the filter could cause such an effect. To this end we have not attempted to measure the nucleotide association and dissociation rate constants of the purified protein.

One of the remarkable features of the ypt 2 primary structure is the region of amino acid residues 38-46 which corresponds to amino acids $32-40$ in the mammalian $\mathrm{H}$-ras protein, known as the 'effector region' (Sigal et al., 1986) with which a GTPase-activating protein (GAP) interacts (Adari et al., 1988; Calés et al., 1988). This region of the S.pombe ypt 2 protein is not only different from that of the other known GTP-binding proteins in S.pombe, like ypt 1 and ypt3 (Miyake and Yamamoto, 1990), ras1 (Fukui and Kaziro, 1985) or ryh1 (Hengst et al., 1990), but it also differs from that of the multiple ras and ras-related proteins isolated from other eukaryotes (see Figure 7). It is, however, identical to the 'effector region' of the S.cerevisiae Sec4 and the Dictyostelium sas 1 protein (Salminen and Novick, 1987; Saxe and Kimmel, 1988). It was therefore of interest to find that the S.pombe ypt2 protein expressed in a conditional-lethal S.cerevisiae sec4 mutant suppresses the temperature-sensitive phenotype. Together with the finding of functional interchangeability of ypt 1 proteins from mouse, S. pombe and S.cerevisiae (Haubruck et al., 1989; Miyake and Yamamoto, 1990) on the one hand, mammalian H-ras and S.cerevisiae Ras1, Ras2 (DeFeo-Jones et al., 1985; Kataoka et al., 1985) as well as human rab6 and S.pombe ryh1 (Hengst et al., 1990) on the other, each group of proteins sharing identical 'effector loops' (Figure 7), this indicates that the 'effector region' is an important determinant of the functional specificity of small GTP-binding proteins. In addition, the strict evolutionary conservation of this sequence motif within groups of members of the superfamily of ras proteins also points to the conservation of proteins interacting with different GTP-binding proteins. Evidence for this assumption is the recent iscovery in S.cerevisiae of a gene, IRAI, whose prote I product shares some homology with mammalian GAF and is integrated in the pathway regulated by Ras protei ; (Tanaka et al., 1989). Interestingly, mammalian GAP is ble to complement iral $^{-}$ yeast mutants, suggesting commo functional properties of these two proteins (Ballester et c ., 1989).

Our observation that the ipombe ypt 2 protein complements a S.cerevisiae sec4 1 utant indicates, but does not prove, that the $S$.pombe prot in acts as a regulator in intracellular protein transport. $\mathrm{Tr}$ : existence in the fission yeast of a Sec4p homologue is of special interest, since no such protein has so far been fou id within the more than 20 mammalian ras-related proteir s. As a perspective, the comparative studies on the functi.sning of different GTPbinding proteins in distantly related eukaryotes amenable also to genetic analysis might prove to be extremely rewarding.

\section{Materials and methods}

\section{Cloning and sequence analysis of the ypt2 gene}

Total DNA from S.pombe strain $972 h^{-s}$, digested with the restriction endonucleases BamHI, EcoRI or HindIII, was separated in a $1 \%$ agarose gel and transferred to nitrocellulose. Hybridization was performed under moderately stringent conditions $\left(6 \times \mathrm{SSC}, 60^{\circ} \mathrm{C}\right)$ with a ${ }^{32} \mathrm{P}$-nick-translated 528 bp EcoRI-HincII fragment of the coding region of the cloned YPTI gene of S.cerevisiae (Gallwitz et al., 1983).

DNA fragments of the HindIII digest in the region of the gel giving a hybridization signal $(\sim 9 \mathrm{~kb})$ were eluted from a preparative agarose gel and cloned into pUC8 (Vieira and Messing, 1982). Recombinant plasmids were transformed into E.coli and colony screening was performed using hybridization fragment and conditions as described above.

The $9.2 \mathrm{~kb}$ HindIII fragment of the recombinant plasmid pPYPT1 was shown to contain a $2.65 \mathrm{~kb}$ cross-hybridizing $N$ col fragment, which was subcloned into pUC8 (pPYPT11). Starting from restriction sites located in the polylinker region and in the cloned DNA fragment, the ypt 2 gene was sequenced by the method of Maxam and Gilbert (1980).

\section{Expression of the ypt2 protein in E.coli}

For the bacterial expression of ypt 2 protein in E.coli, NdeI and BssHII restriction sites were introduced at the $5^{\prime}$ and $3^{\prime}$ ends respectively of the $y p t 2$ coding region. After generating blunt ends, $2.65 \mathrm{~kb} \mathrm{NcoI}$ fragment was cloned into the HincII site of vector pT7T3 (Pharmacia). The NdeI site was introduced by oligonucleotide-directed mutagenesis according to Nakamaye and Eckstein(1986) with the oligonucleotide 5'-GGATTTTGTAGACATATGGGAGTGTTGC-3'. The BssHII site was likewise generated by the oligonucleotide 5'-CAAGATAATAATAGCGCGCCTAACAACAC- $3^{\prime}$. The coding region of the ypt 2 gene as a 612 bp $N d e I-B s s H I I$ fragment was then used to replace the coding region of the S.cerevisiae YPTI gene (a $626 \mathrm{bp} \mathrm{NdeI/BssHII} \mathrm{fragment)} \mathrm{in} \mathrm{the} \mathrm{vector}$ pLNYPT1. Expression of ypt 2 protein in E.coli and nucleotide-binding analysis were done as described previously (Wagner et al., 1987).

\section{Disruption of the ypt2 gene}

The $1.6 \mathrm{~kb} \mathrm{AccI}-\mathrm{ClaI}$ fragment containing the $y p t 2$ gene in plasmid pPYPT1 was replaced in several steps by a $1.8 \mathrm{~kb}$ HindIII fragment of pSUC1-DI harbouring the $S$.pombe ura 4 marker gene.

For $y$ pt 2 gene disruption, S.pombe strain UL130 $\left(h^{+} / h^{-}\right.$ade6-M210/ ade6-M216 ura4-294/ura4-294) was transformed by the lithium acetate method (Ito et al., 1983) with a $4.75 \mathrm{~kb}$ Pst I/HindIII fragment of the ypt 2 locus carrying the ura 4 gene instead of the $y p t 2$ coding region. Correct integration in $\mathrm{ura}^{+}$transformants (strains UL148: $h^{+} / h^{-}$ ade6-M210/ade6-M216 ura4-294/ura4-294 ypt $2^{+} /$ypt $2::$ ura $^{+}$) was verified by Southern analysis with either HindIII or EcoRI/ClaI-digested DNA.

\section{Complementation of S.cerevisiae sec4}

To complement the temperature-sensitive phenotype of sec4 strain NY405 (Salminen and Novick, 1987), a centromere plasmid was constructed that contained the $y p t 2$ gene under the control of the $G A L 10$ promoter. From the recombinant plasmid pEV-Galmypt 1 (Haubruck et al., 1989), a 580 bp $\mathrm{Bgl} \mathrm{II} / \mathrm{NdeI}$ fragment containing the GallO promoter sequence and a 448 bp 
BssHII/XhoI fragment with 188 bp of $3^{\prime}$-untranslated region of the $S$. cerevisiae YPTI gene were ligated together with the 612 bp Ndel/BssHII fragment of the ypt 2 coding region (see above) and cloned into the HindIII site of YCp50 (Rose et al., 1987) to yield plasmid YCp50-GPY2. As the S.cerevisiae strain NY405 (MATa sec4-8 ura3-52) exhibited poor growth in galactose-containing media, it was crossed with AG430-9D MAT $\alpha$ leu2 his3) to create the diploid strain GUS. Sporulation and tetrad analysis yielded one spore GUS-1D (MAT $\alpha$ sec4-8, ura3-52), which grew well on galactose as the sole carbon source. Strain GUS-1D was transformed with either plasmid YCp50 or YCp50-GPY2. Six out of eight tested transformants carrying YCp50-GPY2 were able to grow on galactose- but not on glucosecontaining media at $37^{\circ} \mathrm{C}$, whereas cells transformed with YCp50 were unable to grow at $37^{\circ} \mathrm{C}$ regardless of the carbon source.

\section{Other methods}

Preparation of DNA and RNA, Northern and Southern blots were as described previously (Langford and Gallwitz, 1983; Langford et al., 1984). All media used and general genetic manipulations of S.pombe have been described elsewhere (Gutz et al., 1974). For the isolation of diploid strains, the procedures of Flores da Cunha (1970) were used. Growth of S.cerevisiae cells, strain construction, sporulation of diploids, tetrad analysis and scoring of genetic markers were performed by standard methods (Sherman et al., 1986).

\section{Acknowledgements}

We are indebted to Herbert Gutz (Braunschweig) and Peter Novick (New Haven) for providing some of the yeast strains used in this study. We thank Masayuki Yamamoto (Tokyo) for helpful discussions and for exchanging sequence information before publication. We also thank Hans-Peter Geithe for synthesizing oligonucleotides, Heike Behr for competent technical assistance and Ingrid Balshüsemann for invaluable secretarial help. Part of this work was supported by grants to D.G. of the Bundesministerium für Forschung und Technologie (BMFT) and the Fonds der Chemischen Industrie.

\section{References}

Adari,H., Lowy,D.R., Willumsen,B.M., Der,C.J. and McCormick,F. (1988) Science, 240, 518-521.

Baker,D., Wuestehube,L., Scheckman,R., Botstein,D. and Segev,N. (1990) Proc. Natl. Acad. Sci. USA, 87, 355-359.

Ballester,R., Michaeli,T., Ferguson,K., Xu,H.-P., McCormick,F. and Wigler,M. (1989) Cell, 59, 681-686.

Barbacid,M. (1987) Annu. Rev. Biochem., 56, 779-827.

Beckner,S.K., Hattori,S. and Shih,T.Y. (1985) Nature, 317, 71-72.

Birchmeier,C., Broek,D. and Wigler,M. (1985) Cell, 43, 615-621.

Bourne,H.R. (1988) Cell, 53, 669-671.

Calés,C., Hancock,J.H., Marshall,C,J. and Hall,A. (1988) Nature, 332, 548-551.

Chardin,P. (1988) Biochimie, 70, 865-868.

Chardin,P., Madaule,P. and Tavitian,A. (1988) Nucleic Acids Res., 16, 2717.

DeFeo-Jones,D., Scolnick,E.M., Koller,R. and Dhar,R. (1983) Nature, 306, 707-709.

DeFeo-Jones,D., Tatchell,K., Robinson,L.C., Sigal,I.S., Vass,W.C., Lowy,D.R. and Scolnick,E.M. (1985) Science, 228, 179-184.

Dever,T.E., Glynias,M.J. and Merrick,W.C. (1987) Proc. Natl. Acad. Sci. USA, 84, 1814-1818.

De Vos,A.M., Tong,L., Milburn,M.V., Matias,P.M., Jangarik,J., Noguchi,S., Nishimura,S., Miura,K., Ohtsuka,E. and Kim,S.-H. (1988) Science, 239, 888-893.

Fawell,E., Hook,S. and Armstrong,J. (1989) Nucleic Acids Res., 17, 4373.

Flores da Cunha,M. (1970) Genet. Res., 16, 127-144.

Fukui,Y. and Kaziro,Y. (1985) EMBO J., 4, 687-691.

Fukui,Y., Kozasa,T., Kaziro,Y., Takeda,T. and Yamamoto,M. (1986) Cell, 44, 329-336.

Gallwitz,D., Donath,C. and Sander,C. (1983) Nature, 306, 704-707.

Gallwitz,D., Haubruck,H., Molenaar,C., Prange,R., Puzicha,M., Schmitt,H.D., Vorgias,C. and Wagner,P. (1989) In Bosch,L., Kraal,B. and Parmeggiania, A. (eds), The Guanine-nucleotide Binding Proteins. Plenum Press, New York, NATO ASI Series A: Life Sciences, Vol. 165 , pp. 257-264.

Goud,B., Salminen,A., Walworth,N.C. and Novick,P.J. (1988) Cell, 53, $753-768$.

Gutz,H., Heslot,H., Leupold,U. and Loprieno,N. (1974) In King,R.D. (ed.), Handbook of Genetics. Plenum Press, New York, Vol. 1, pp. 395-446.
Haubruck,H., Disela,C., Wagner,P. and Gallwitz,D. (1987) EMBO J., 6 , 4049-4053.

Haubruck,H., Prange,R., Vorgias,C. and Gallwitz,D. (1989) EMBO J., 8, $1427-1432$

Hengst,L., Lehmeier, T. and Gallwitz,D. (1990) EMBO J., 9, 1949-1955. Ito,H., Fukuda,Y., Murata,K. and Kimura,A. (1983) J. Bacteriol., 153, $163-168$.

Kataoka,T., Powers,S., Cameron,S., Fasano,O., Goldfarb,M., Broach,J. and Wigler,M. (1985) Cell, 40, 19-26.

Langford,C.J. and Gallwitz,D. (1983) Cell, 33, 519-527.

Langford,C.J., Klinz,F.-J., Donath,C. and Gallwitz,D. (1984) Cell, 36, 645-653.

Madaule,P., Axel,R. and Myers,A.M. (1987) Proc. Natl. Acad. Sci. USA, 84, 779-783.

Maxam,A. and Gilbert,W. (1980) Methods Enzymol., 65, 499-560.

Miyake,S. and Yamamoto,M. (1990) EMBO J., 9, 000-000.

Molenaar,C.M.T., Prange,R. and Gallwitz,D. (1988) EMBO J., 7, 971-976.

Nakamaye,K.L. and Eckstein,F. (1986) Nucleic Acids Res., 14, 9679-9698.

Pai,E.F., Kabsch,W., Krengel,U., Holmes,K.C., John,J. and Wittinghofer,A. (1989) Nature, 341, 209-214.

Powers,S., Kataoka,T., Fasano,O., Goldfarb,M., Strathern,J., Broach,J. and Wigler,M. (1984) Cell, 36, 607-612.

Rose,M.D., Novick,P., Thomas,J.H., Botstein,D. and Fink,G.R. (1987) Gene, 60, 237-243.

Russel,P. and Nurse,P. (1986) Cell, 45, 781-782.

Salminen,A. and Novick,P.J. (1987) Cell, 49, 527-538.

Saxe,S.A. and Kimmel,A.R. (1988) Dev. Genet., 9, 259-265.

Schmitt,H.D., Wagner,P., Pfaff,E. and Gallwitz,D. (1986) Cell, 47, 401-412.

Schmitt,H.D., Puzicha,M. and Gallwitz,D. (1988) Cell, 53, 635-647. Segev,N., Mulholland,J. and Botstein,D. (1988) Cell, 52, 915-924.

Sherman,F., Fink,G.R. and Hicks,J.B. (1986) Laboratory Course Manual for Methods in Yeast Genetics. Cold Spring Harbor Laboratory Press, Cold Spring Harbor, NY.

Sigal,I.S., Gibbs,J.B., D’Alonzo,J.S., Temeles,G.L., Wolanski,B.S., Socher,S.H. and Scolnick,E.M. (1986) Proc. Natl. Acad. Sci. USA, 83, $952-956$

Tanaka,K., Matsumoto,K. and Toh,E.-A. (1989) Mol. Cell. Biol., 9, $757-768$.

Toda,T., Uno,I., Ishikawa,T., Powers,S., Kataoka,T., Broek,D., Cameron,S., Broach,J., Matsumoto,K. and Wigler,M. (1985) Cell, 40, $27-36$.

Touchot,N., Chardin,P. and Tavitian,A. (1987) Proc. Natl. Acad. Sci. USA, 84, 8210-8214.

Trahey,M., Wong,G., Halenbeck,R., Rubinfeld,B., Martin,G., Ladner,M., Long,C.M., Crosier,W.J., Watt,K., Koths,K. and McCormick,F. (1988) Science, 242, 1697-1700.

Vieira,J. and Messing,J. (1982) Gene, 19, 259-268.

Vogel,U.S., Dixon,R.A.F., Schaber,M.D., Diehl,R.E., Marshall,M.S., Scolnick,E.M., Sigal,I.S. and Gibbs,J.B. (1988) Nature, 335, 90-93.

Wagner,P., Molenaar,C.M.T., Rauh,A.J.G., Brökel,R., Schmitt,H.D. and Gallwitz,D. (1987) EMBO J., 6, 2373-2379.

Walworth,N.C., Goud,B., Kabcenell,A.K. and Novick,P.J. (1989) EMBO $J ., 8,1685-1693$.

Yeramian,P., Chardin,P., Madaule,P. and Tavitian,A. (1987) Nucleic Acids Res., 15, 1869.

Zahraoui,A., Touchot,N., Chardin,P. and Tavitian,A. (1989) J. Biol. Chem., 264, 12394-12401.

Received on January 17, 1990; revised on February 26, 1990 